\title{
A STUDY AND COMPARISON OF OLSR, AODV AND ZRP ROUTING PROTOCOLS IN AD HOC NETWORKS
}

\author{
Hrituparna Paul , Priyanka Sarkar ${ }^{2}$ \\ ${ }^{1,2}$ Assistant Professor, National Institute of Technology, Agartala \\ hrituparnanita@gmail.com,priyanka.csenita@gmail.com
}

\begin{abstract}
A mobile ad hoc networks (MANET) is characterized by multihop wireless connectivity consisting of independent nodes which move dynamically by changing its network connectivity without the uses of any pre-existent infrastructure. MANET offers[1, 2] such flexibility which helps the network to form anywhere, at any time, as long as two or more nodes are connected and communicate with each other either directly when they are in radio range or via intermediate mobile nodes. Routing is a significant issue and challenge in ad hoc networks and many routing protocols have been proposed like OLSR, AODV, DSDV,DSR, ZRP, and TORA, LAR so far to improve the routing performance and reliability. This research paper describes the characteristics of ad hoc routing protocols OLSR, AODV and ZRP based on the performance metrics like packet delivery ratio, end-to-end delay, throughput and jitter by increasing number of nodes in the network. This comparative study proves that OLSR, ZRP performs well in dense networks in terms of low mobility and low traffic but in high mobility and high traffic environment ZRP performs well than OLSR and AODV.
\end{abstract}

Keywords: MANET, AODV, OLSR, ZRP, routing

\section{INTRODUCTION:}

The rapid increases in the applications of Personal Digital Assistants (PDAs) devices such as tabs, compact laptops etc has made popularity of wireless networks. One of the major types of wireless networks is Mobile Ad-Hoc networks (MANET). Every node in this network acts as a router or relay station to forward data to the designated node. In this network nodes are mobile and constantly change its location from one MANET to another. The application of this network is such as emergency situation, disaster recovery, crowd control, battle fields etc.

Many routing protocols have been proposed for the mobile ad hoc network and classified as Proactive or Table Driven routing Protocol, Reactive or On Demand Routing Protocol, Hybrid Routing protocol.

\section{A. Proactive or Table-Driven Routing Protocols}

Proactive routing is also often termed as table- driven routing. In this type of routing protocols, fresh lists of destinations and their routes are maintained by periodic distribution of routing tables throughout the network and this category of protocol always strives to maintain consistent and updated routing information at each node [3]. The proactive routing protocols use link-state routing algorithms which frequently flood the link information about its neighbors and the main drawback of proactive routing protocol is that all the nodes in the network always maintain an updated table.

\section{Destination-Sequenced}

Distance-Vector Routing Protocol (DSDV) [4] and Optimized Link-State Routing (OLSR) [5] are the two common proactive routing protocols.

\section{B. Reactive or On Demand Routing Protocol}

This type of routing is often known as on- demand routing or source-initiated routing protocol. The main advantage of reactive protocols is that it imposes less overhead due to route messages on the network but at the same time, it is also facing high latency time in route finding process and sometimes excessive flooding of the communication packets may lead to network blockage. Unlike table driven protocols, all nodes need not maintain up-to- date routing information here. Adhoc On- Demand Distance Vector Routing (AODV) [4], Dynamic Source Routing (DSR) [6] and Temporally Ordered Routing Algorithm (TORA) [7], are some of the examples of reactive routing protocol.

\section{Hybrid Routing Protocol}

Hybrid routing protocol combines the advantages of both proactive and reactive routing protocols. The routing is initially established with some proactively prospected routes and then serves the demand from additionally activated nodes through reactive flooding. Some of the existing hybrid protocols are ZRP [8] and TORA [9]. 


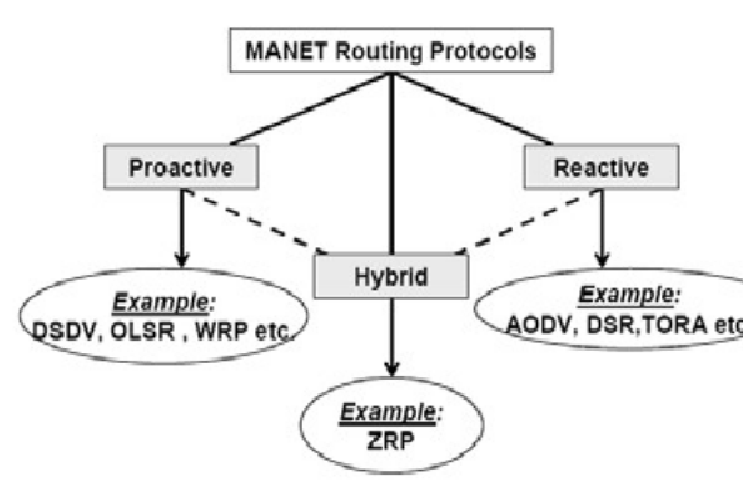

Figure 1 Classification of MANET routing protocols

The figure 1 shows the prominent way of classifying MANETs routing protocols. The protocols may be categorized into two types, Proactive and Reactive. Other category of MANET routing protocols which is a combination of both proactive and reactive is referred as Hybrid.

This paper is categorized as follows. Section I present the Introduction and overview of Proactive, Reactive and Hybrid routing protocols. Section II provides an overview of Routing protocols. Section III provides description about Metrics for performance comparison Section IV presents Comparative Study of Ad Hoc Routing Protocols. Section IV concludes the paper

\section{OVERVIEW OF ROUTING PROTOCOLS:}

\section{A. Optimized Link State Routing Protocol}

Optimized link state routing [10] is a proactive protocol in which, each node intermittently broadcasts its routing table, allowing each node to build an inclusive view of the network topology. The episodic nature of this protocol creates a large amount of overhead and in order to reduce overhead, it limits the number of mobile nodes that can forward network wide traffic and for this purpose it use multi point relays (MPRs), which are responsible for forwarding routing messages and optimization for flooding operation. Mobile nodes, which are selected as MPRs can forward control traffic and reduces the size of control messages. MPRs are chosen by a node, such that, it may reach each two hop neighbor via at least one MPR, then it can forward packets, if control traffic received from a previous hop has selected the current node as a MPR. Mobility causes, route change and topology changes very frequently and topology control (TC) messages are broadcasted throughout the network. All mobile nodes maintain the routing table that contains routes to all reachable destination nodes. This protocol does not notify the source immediately after detecting a broken link. Source node comes to know that route is broken, when the intermediate node broadcasts its next packets. Thus, by determining the path through the multipoint relays, it is possible to keep away the difficulties experienced during the packet transmission over a uni-directional link.

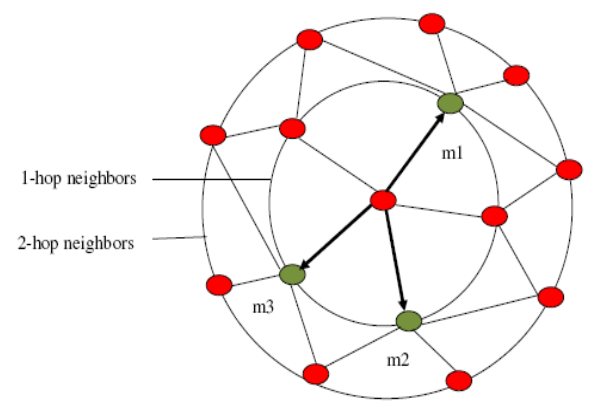

Fig2:-Multipoint Relays of the OLSR network

\section{Advantages and Limitations:}

OLSR is a flat routing protocol and it does not need central administrative system to handle its routing process. The link is reliable for the control messages, since the messages are sent periodically and the delivery does not have to be sequential. This protocol is best suitable for high density network and does not allows long delays in the transmission of the packets.

However, as a limitation this protocol needs that each node periodically sends the updated topology information throughout the entire network, this increase the protocols bandwidth usage. But the flooding is minimized by the MPR's, which are only allowed to forward the topological messages.

\section{B. Ad hoc On-Demand Distance Vector Routing (AODV)}

AODV is a up to date routing protocol that adopts a purely reactive approach and capable of both unicast and multicast routing: it sets up a route on-demand at the start of a communication session, and uses it till it breaks, after which a new route setup is initiate .AODV adopts a very different mechanism to maintain routing information. It uses traditional routing tables, one entry per destination [11-15]. Without source routing, AODV relies on routing table entries to propagate a route replay (RREP) back to the source and, subsequently, to route data packets to the destination. AODV uses sequence numbers maintained at each destination to determine the freshness of routing information and to prevent routing loops. All routing packets carry these sequence numbers. An important feature of AODV is the maintenance of timer-based states in each node, regarding utilization of individual routing table entries. A routing table entry is expired if not used recently. A set of predecessor nodes is maintained for each routing table entry, indicating the set of neighboring nodes which use that entry to route data 
packets. These nodes are notified with route error (RERR) packets when the next hop link breaks. Each predecessor node, in turn, forwards the RERR to its own set of predecessors, thus effectively erasing all routes using the broken link. Route error propagation in AODV can be visualized conceptually as a tree whose root is the node at the point of failure and all sources using the failed link [16].

\section{The algorithm's primary objectives are as follows:}

- To broadcast discovery packets only when necessary.

- To distinguish between local connectivity management Neighborhood detection and general topology maintenance.

- To disseminate information about changes in local connectivity to those neighboring mobile nodes that are likely to need the information.

\section{Advantages and Limitations}

The main advantage of AODV protocol is that routes are established on demand and destination sequence numbers are used to find the latest route to the destination and it also supports both unicast and multicast packet transmissions even for nodes in constant movement. It responds quickly to the topological changes in the network and updating only the nodes that may be affected by the change, using the RRER message. The Hello messages, which are responsible for the route maintenance, are also limited so that they do not create unnecessary overhead in the network.

The limitations of AODV protocol is all nodes in the broadcast medium can detect each other's broadcasts. It is also possible that a valid route is expired and the determination of a reasonable expiry time is difficult. The reason behind this is that the nodes are in mobility and their sending rates may differ widely. In addition, as the size of network grows, various performance metrics begin decreasing. A route discovered with AODV may no longer be the optimal route further along in time. This situation can arise because of network congestion or the fluctuating characteristics of wireless links.

\section{ZRP}

ZRP [14] divides the topology into zones and uses different routing protocols within and between the zones based on their weaknesses and strengths. Each node in ZRP has a predefined zone centered at itself.. ZRP maintains a zone around each node that consists of all nodes within ' $\mathrm{k}$ ' hops away from that node. Proactive routing is used within the zone whereas reactive routing is used amongst zones. For data delivery, it is checked whether the destination node exists within the zone or not. If yes, data is sent immediately otherwise RREQ packet is sent to border nodes. Border nodes check within their own zones for destinations. If found, border node sends RREP on reverse path otherwise it adds its own address to the packet and forwards to its own border nodes. Process continues until packet reaches to the destination itself or to a node having destination within its zone. Path in the RREP packet is used for sending data to destinations.

\section{Advantages and Limitations}

ZRP tries to combine the advantages of reactive and proactive routing protocols. With properly configured zone radius, ZRP may outperform both proactive routing protocols and reactive routing protocols.

The potential disadvantage is that since hierarchical routing is used, the path to a destination may be suboptimal. Furthermore, since each node has higher level topological information, memory requirement is greater

\section{METRICS FOR PERFORMANCE COMPARISON}

MANET has number of qualitative and quantitative metrics that can be used to compare ad hoc routing protocols. The table I illustrates the comparison of OLSR, AODV and ZRP routing protocols. This paper has been considered the following metrics to evaluate the performance of ad hoc network routing protocols.

\section{1) End-to-end Delay:}

This metric represents average end-to-end delay and indicates how long it took for a packet to travel from the source to the application layer of the destination. It includes all possible delay caused by buffering during route discovery latency, transmission delays at the MAC, queuing at interface queue, and propagation and transfer time. It is measured in seconds.

\section{2) Packet Delivery Ratio:}

Packet delivery ratio is calculated by dividing the number of packets received by the destination through the number of packets originated by the application layer of the source (i.e. CBR source). It specifies the packet loss rate, which limits the maximum throughput of the network.

\section{3) Throughput:}

It is the measure of the number of packets successfully transmitted to their final destination per unit time. It is the ratio between the number of received packets vs sent packets.

\section{4) Packet Jitter:}

It is the ratio of transmission delay of the current packet and the transmission delay of the previous packet. Jitter can be calculated only if at least two packets have been received 


\section{COMPARATIVE STUDY OF AD HOC}

\section{ROUTING PROTOCOLS}

\section{TABLE 1 COMPARISON OF AD HOC ROUTING PROTOCOLS}

\begin{tabular}{|c|c|c|c|}
\hline \begin{tabular}{|l|} 
Performance \\
Constraints
\end{tabular} & OLSR & AODV & ZRP \\
\hline Category & $\begin{array}{l}\text { Table driven or } \\
\text { Proactive }\end{array}$ & $\begin{array}{l}\text { On Demand } \\
\text { or Reactive }\end{array}$ & hybrid \\
\hline $\begin{array}{l}\text { Protocol } \\
\text { Type }\end{array}$ & $\begin{array}{l}\text { Link } \\
\text { scheme }\end{array}$ & $\begin{array}{l}\text { Distance } \\
\text { Vector }\end{array}$ & Link Reversal \\
\hline $\begin{array}{l}\text { Route } \\
\text { Maintained }\end{array}$ & Route Table & Route Table & Route Table \\
\hline Loop & Yes & Yes & Yes \\
\hline $\begin{array}{l}\text { Route } \\
\text { Philosophy }\end{array}$ & Flat & Flat & Flat \\
\hline Multiple & No & No & Yes \\
\hline Multicast & Yes & Yes & $\mathrm{NO}$ \\
\hline $\begin{array}{l}\text { Message } \\
\text { Overhead }\end{array}$ & Minimum & Moderate & Moderate \\
\hline $\begin{array}{l}\text { Periodic } \\
\text { broadcast }\end{array}$ & Possible & Possible & Possible \\
\hline $\begin{array}{l}\text { Requires } \\
\text { sequence }\end{array}$ & No & Yes & Yes \\
\hline \begin{tabular}{|l|} 
Route \\
reconfigurati \\
on \\
methodology \\
\end{tabular} & $\begin{array}{l}\text { Control messages } \\
\text { sent in advance } \\
\text { to } \\
\text { increase the }\end{array}$ & $\begin{array}{l}\text { Erase } \\
\text { notify } \\
\text { Source }\end{array}$ & $\begin{array}{l}\text { Link } \\
\text { and information } \\
\text { stored in link } \\
\text { table }\end{array}$ \\
\hline
\end{tabular}

TABLE.2 ROUTING PERFORMANCE IN LOW MOBILITY

\begin{tabular}{|l|l|l|l|l|}
\hline \multicolumn{5}{|c|}{ Low Mobility and Low Traffic } \\
\hline Protocol & $\begin{array}{l}\text { End } \\
\text { to End } \\
\text { delay }\end{array}$ & $\begin{array}{l}\text { Packet } \\
\text { delivery } \\
\text { ratio }\end{array}$ & Throughput & Jitter \\
\hline OLSR & Low & High & Good & Low \\
\hline AODV & Average & High & Average & High \\
\hline ZRP & Low & High & Average & Low
\end{tabular}

\section{TABLE.3ROUTING PERFORMANCE IN HIGH} MOBILITY

\begin{tabular}{|l|l|l|l|l|}
\hline \multicolumn{5}{|l|}{ High Mobility and High Traffic } \\
\hline Protocol & $\begin{array}{l}\text { End } \\
\text { to End } \\
\text { delay }\end{array}$ & $\begin{array}{l}\text { Packet } \\
\text { delivery } \\
\text { ratio }\end{array}$ & Throughput & Jitter \\
\hline OLSR & Low & Average & Good & Low \\
\hline AODV & Average & Average & Average & High \\
\hline ZRP & High & Low & Average & Average \\
\hline
\end{tabular}

\section{CONCLUSIONS}

This paper presents the comparative study and

Performance analysis of various ad hoc routing protocols (OLSR, AODV and ZRP) on the basis of end-to-end delay, packet delivery ratio, throughput, jitter performance metrics. The study of these routing protocols shows that OLSR is more efficient in high density networks with highly sporadic traffic. OLSR requires that it continuously have some bandwidth in order to receive the topology updates messages. As well, AODV keeps on improving in packet delivery ratio with dense networks. The performance of all protocols was almost stable in sparse medium with low traffic. It has been concluded that performance of ZRP is better for high mobility and high traffic networks where as the OLSR and ZRP performs well in low mobility and low traffic networks. The future work suggested that the effort will be made to enhance ad hoc network routing protocol by tackle core issues.

\section{REFERENCES:}

[1] Alexander Klein, "Performance Comparison and Evaluation of AODV, OLSR and SBR in Mobile Ad-Hoc Networks", Innovation Works, IEEE 3rd International Symposium on Wireless Pervasive Computing, 2008.

[2] Anne Aaron, Jie Weng, "Performance Comparison of Ad-hoc Routing Protocols for Networks with Node Energy Constraints", available at http://ivms.stanford.edu, Spring 2000-2001.

[3] Shah, R.C., Rabaey, J.:Energy Aware Routing for Low Energy Ad Hoc Sensor Networks. In: IEEE Wireless Communications and Networking Conference (WCNC 2002), vol. 1, pp. 350-355 (2002)

[4]. Perkins, C.E., Bhagwat, P.Highly Dynamic DestinationSequenced Distance-Vector Routing (DSDV) for Mobile Computers. In: SIGCOMM 1994, pp. 234-244 (August 1994)

[5]. Clausen, T., Jacquet, P.: Optimized link state routing protocol, IETF $\quad$ RFC $3626 \quad$ (2003), http://www.ietf.org/rfc/rfc3626.txt

[6].Perkins, C.E., Royer, E.M.: Ad Hoc On-Demand Distance Vector Routing. In: 2nd IEEE Workshop on Mobile Computing Systems and Applications (WMCSA 1999), pp. 90-100 (February 1999)

[7]. Camp, T., Boleng, J., Davies, V.: A Survey of Mobility Models for Ad-hoc Network Research. Wireless Communication and Mobile Computing [WCNC]: Special Issue on Mobile Ad-hoc Networking: Research, Trends and Applications 2(5), 483-502 (2002)

[8]. H. Ehsan and Z. A. Uzmi (2004), "Performance Comparison of Ad Hoc Wireless Network Routing Protocols", IEEE 8th International Multi topic Conference, Proceedings of INMIC, pp.457 - 465, December 2004.

[9]. Z. J. Hass and M. R. Pearlman, "Zone Routing Protocol (ZRP)", Internet draft available at www.ietf.org, 
November 1997.

[10]. Open Link State Routing. http://www.olsr.org

[11]. Perkins CE, Royer EM, Das SR. Ad Hoc on Demand Distance Vector (AODV) routing. Available from: http://www.ietf.org/internetdrafts/draft-ietfmanet-aodv-06.txt, IETF Internet Draft, work in progress, 2000.

[12]. Perkins C, Belding-Royer E, Das S. Ad hoc OnDemand Distance Vector (AODV) routing. Network working group, IETF RFC,RFC 3561, 2003.

[13]. Gallissot M. Routing on ad hoc networks, Project, Supervisor,Maurice Mitchell Date, 2007.

[14]. Zygmunt J Haas, Marc R. Pearlman, and Prince Samar, "The Zone Routing Protocol (ZRP) for Ad Hoc Networks", draftietf-manet-zone-zrp-04.txt,july,2002

[15]. Jaisankar N, Saravanan R. An extended AODV protocol for multipath routing in MANETs. Int J Eng Technol 2010;2(40).

[16]"Zone Routing protocol(ZRP)," http://tools.ietf.org/id/draftietf-manetzone- zrp-04.txt. 